\title{
Trajetória de vida \\ e construção dos saberes de professoras de educação física
}

CDD. 20.ed. 796.017

Mário Lucio de AMORIM FILHO*
Glauco Nunes Souto RAMOS*
*Departamento de Educação Física e Motricidade Humana, Universidade Federal de São Carlos.

\section{Resumo}

Considerando que os saberes dos professores são construídos ao longo dos diversos momentos de sua vida discente e docente, e que essa temática deveria ser mais abordada durante a formação inicial de professores, o objetivo deste estudo foi analisar a trajetória de vida de duas professoras de educação física escolar, sendo uma experiente (PE), com quase 30 anos de carreira, e uma novata (PN), com aproximadamente um ano e meio de carreira, dos ensinos fundamental e médio da rede pública da cidade de São Carlos-SP. Para tanto, a pesquisa pautou-se na abordagem qualitativa e teve como instrumento de coleta de dados a entrevista semi-estruturada. A análise dos dados conduziu à elaboração das seguintes categorias: 1) a infância e os possiveis reflexos na atuação profissional, que apresentou a escola e a relação com os pais como grandes responsáveis pela transmissão de valores do que é ser professor; 2 ) visão de curso/universidade, destacando o apreço sobre o período acadêmico na visão da PE e da PN; 3) dificuldades/reflexões sobre a vida docente, que revelou os obstáculos encontrados pela PN em seu início de carreira e, também, as artimanhas utilizadas pela PE ao lidar com as incertezas que envolvem a prática docente. Desta forma, ressaltamos que as trajetórias de vida dos professores, quando analisadas como uma perspectiva metodológica, podem apresentar aspectos importantes para futuros professores e também auxiliar os docentes durante as suas intervenções pedagógicas, pois o docente que relaciona e reflete a sua trajetória de vida com a sua atuação na escola pode reconstruir as suas intervenções e tornar-se um profissional melhor.

UnIteRmos: Histórias de vida; Saberes docentes; Educação física escolar.

\section{Introdução}

Do mesmo modo que alguns autores como BORGES (1998), Nóvoa (1995), Goodson (1995) e SiLVa (2000) têm dado uma notável relevância em seus trabalhos no que se refere à história de vida dos docentes e a construçôes de seus saberes, sentimos a necessidade em contribuir para tal temática que, ao nosso ver, tem sido pouco discutida nos cursos de formação de professores.

Corroboramos com os estudiosos citados acima que consideram a trajetória que os profissionais percorrem, aí incluído o período que compreende a infância e a adolescência, o momento de formação acadêmica e a etapa da prática docente, como sendo uma forte influenciadora de suas açōes durante o exercício de suas profissōes.

SiLva (2000, p.32), salienta que "para descobrir os 'porquês' e o 'como' da prática docente devemos investigar onde o professor se alicerça para pensar como pensa e fazer como faz".
Embora se trate de um fenômeno carregado de subjetividade, a produção de conhecimento a partir da história de vida não pode ser apenas uma biografia e uma relativização da prática docente, mas sim servir como ponto de partida para compreender suas influências na docência, bem como, possibilitar ao professor uma reflexão sobre a sua própria trajetória e suas influências na sua ação profissional.

Neste sentido, o objetivo do estudo em questão foi analisar as trajetórias pessoais e profissionais de duas professoras de Educação Física dos ensinos fundamental e médio da rede pública, sendo uma novata e outra mais experiente, ambas da cidade de São Carlos - SP, com o intento de verificar os fatores de destaque que vêm constituindo suas histórias de vida.

Almejamos por meio desse artigo, defender a ideia de que os professores, em suas relaçôes sociais, 
também são produtores de saber. Portanto, investigar a história de vida de professoras de Educação Física (suas próprias experiências enquanto discentes e docentes, suas formações, seus históricos familiares, suas ideologias, etc.) pareceu-nos ser uma forma coerente para melhor compreender os fatores relevantes que podem influenciar nas suas atuações profissionais.

\section{História de vida e as trajetórias pessoais e profissionais dos professores}

A superação das pesquisas do tipo processoproduto marca o início de novas reflexões nos estudos da educação, ou seja, a preocupação exclusiva centrada na ação do professor - como organizador de comportamentos - com relação à aprendizagem eficaz dos alunos cede lugar aos olhares voltados para os saberes que esse professor possui e constrói ao longo de sua ação profissional.

Neste sentido, em meados da década de 80, outros tipos de pesquisas começaram a aparecer. Nomenclaturas e estruturas diversas de pesquisas foram se constituindo e se interpenetrando, dando origem a diversos enfoques como: psico-cognitivos, subjetivo-interpretativo, curricular, profissional, dentre outros (BORGES, 2001).

Além dessa mudança metodológica, conforme salienta MARCELO-GarCia (1998), houve também uma ampliação referente aos modelos de análise, “(...) se inicialmente a preocupação centrava-se principalmente nos professores em formação, pouco a pouco foi aparecendo considerável literatura de pesquisa a respeito dos professores principiantes e dos professores em exercício" (p.51).

Ainda com base nos escritos do mesmo autor, podemos destacar que uma referência importante para esse novo momento metodológico e temático das pesquisas sobre a formação de professores diz respeito à consolidação de um novo paradigma denominado "pensamento do professor". É nesse paradigma que surgem propostas metodológicas apoiadas na concepção do professor como profissional reflexivo, sendo a história de vida uma dessas propostas.

$\mathrm{Na}$ docência em Educação Física tal temática ainda é pouco investigada, contudo, estudos como os de Betti e Mizukami (1997), Santos, Bracht e Almeida (2009) e Folle e Nascimento (2009) reforçam os apontamentos destacados pela área da Educação que sustentam uma linha de pesquisa mais consolidada sobre a história de vida docente ou trajetórias pessoais e profissionais dos professores, qual seja: reconhecer que tais elementos constituem o processo de ser e se fazer professor e revelam explicitamente seus modos de sentir, pensar e agir.
BETTI e MizUKAMI (1997) ao descreverem e analisarem a trajetória de vida profissional de uma professora de Educação Física levantaram informações que podem ser úteis na formação de professores. As autoras indicam que existem pontos intrínsecos à pessoa como: a escolha vocativa da profissão, o interesse pela formação continuada, a satisfação em ministrar aulas e a influência familiar; e também há pontos extrínsecos como: o convívio com os seus pares, a interdisciplinaridade e as condiçôes de infra-estrutura escolar, que interferem na vida profissional. As pesquisadoras concluem que, apesar do estudo corresponder a uma história de vida (que é única e singular), ele evidencia pontos fortes que podem ser encontrados em outras histórias de vida de professores e, por isso, servir como exemplo para futuras gerações de docentes.

Já Santos, Bracht e Almeida (2009) ao entrevistarem três professores de Educação Física sinalizaram que as experiências sociais, culturais e corporais, cuja origem remonta suas histórias de vida, são determinantes na escolha profissional e posterior envolvimento no curso de formação inicial. Dois dos professores entrevistados afirmaram que a escolha pelo curso de Educação Física veio da paixão pelo esporte e envolvimento com ele antes mesmo da entrada na universidade. Este fator também foi determinante para que eles tivessem um bom envolvimento com o curso de formação inicial. Já a terceira professora entrevistada nunca gostou de esportes e afirmou ter escolhido o curso de Educação Física por questôes financeiras, uma vez que o curso de Medicina (seu grande sonho) era muito caro. Evidenciou-se que esta docente não gostou do curso de graduação, provavelmente pela falta de afinidade com a área desde a época que antecedeu sua entrada na universidade.

Em um segundo momento desse estudo, os autores apoiando-se no ciclo de vida profissional dos professores, elaborado por HUBERMAN (1995), relacionaram a vida dos seus professores-colaboradores com algumas fases desse ciclo, como a entrada na carreira, a fase de estabilização, a fase de diversificação até o momento do desinvestimento da carreira (mais 
adiante, neste artigo, retomaremos os estágios do ciclo proposto por HUBERMAN (1995), relacionando com as histórias de vida das docentes entrevistadas neste estudo). Por fim, Santos, Bracht e Almeida (2009) concluem que além de se estudar aspectos meramente profissionais também se mostra importante a compreensão sobre a pessoa que é o professor, a fim de que alguns aspectos como: a escolha da profissão, a direção que é dada a carreira, o desinvestimento no ensino, o abandono da docência, entre outros, também possam ser compreendidos de forma mais abrangente e elaborada.

Seguindo esta linha de pesquisa, Folle e NASCIMENTO (2009) considerando que a progressão da docência também é afetada por experiências pessoais destacaram, ao entrevistar quatro professores de Educação Física com mais de 25 anos de carreira, os momentos marcantes das suas trajetórias profissionais. Os autores constataram que os piores momentos do percurso profissional desses professores de Educação Física concentraram-se nos primeiros cinco anos de carreira e no período final da atividade docente, no qual foram apontadas as condiçôes de trabalho oferecidas, o descontentamento com as políticas educacionais e as decepções com a classe docente como sendo os aspectos mais relevantes. Já os melhores momentos vivenciados durantes as trajetórias dos professores de Educação Física aconteceram em diferentes períodos da carreira e compreenderam as homenagens recebidas, os cargos assumidos, as apresentações realizadas em datas comemorativas e as participaçóes e conquistas em competiçóes esportivas. Os autores concluem afirmando que, apesar desses momentos corresponderem às experiências individuais dos professores investigados, eles podem revelar acontecimentos comuns também vivenciados por outros profissionais que atuam no âmbito escolar.

Nesta perspectiva, associada às histórias de vida, a temática Vida de professores aqui apresentada foi dividida com base na literatura consultada em três momentos distintos: infância e adolescência, período acadêmico e o momento da atuação profissional, contendo as respectivas caracterizaçóes de tais etapas. Entretanto, cabe ressaltar que o professor deve ser visto de forma abrangente e não segmentada, ou seja, os saberes são construídos durante suas trajetórias de vida, pelas diversas relações sociais nas quais ele está inserido, conduz a um único ponto - o ser professor (AMORIM Filho, 2007). Desse modo, a periodização que será mostrada a seguir teve função organizativa para a estruturação deste estudo.

\section{Infância e adolescência}

No período referente a infância e adolescência ocorre diversas apropriaçōes de valores e conhecimentos. Esses saberes, segundo SiLVA (2000, p.30), "vão se transformando em estruturas de pensar e agir. São saberes que se transformam em crenças, ou seja, adquirem uma base de confiança, e acabam por influenciar ou determinar as decisões e ações dos homens".

Dentro desta perspectiva, Santos, Bracht e ALMEIDA (2009) ao investigarem o ciclo de vida de três professores de Educação Física que, há mais de 20 anos, dedicam considerável tempo de suas vidas a essa profissão na escola salientam que as experiências vividas (danças, esportes...) antes do ingresso dos professores na universidade influenciaram no momento das suas opções em seguir a carreira da docência em Educação Física, uma vez que, além de familiar, estavam relacionadas à realização pessoal às suas histórias de vida.

Deste modo, quando os alunos ingressam no curso acadêmico de formação de professores em geral e/ou no de Educação Física, eles já vêm com uma certa compreensão do que é ser professor. Esses saberes foram sendo construídos à medida que esses aprendizes tiveram experiências com diversos professores, durante sua infância e adolescência. Além disso, podemos dizer que a própria relação social, dentro e fora da escola, já transmite certa quantidade de informações do que é ser professor.

Assim, o educador em sua atuação na escola não é neutro em sua relação com os alunos. Deste modo, seja em um diálogo, em uma instrução ou em uma crítica, ele articula em sua maneira de agir os costumes, as crenças nas quais ele acredita, os valores que seus pais, na sua infância, lhe transmitiram (e que foram por eles reelaborados), além dos conceitos que foram apropriados por meio de suas relações sociais ao longo dos anos.

Um professor de Educação Física, por exemplo, pode servir-se de uma estratégia em sua aula semelhante àquela que um ex-professor seu utilizou. Esse docente pode se lembrar de uma situação em que seu professor de Educação Física do colégio o recriminou na frente de seus colegas por ele ter xingado um amigo. Futuramente, quando essa criança ou adolescente tornar-se um professor, ele poderá utilizar a mesma estratégia em uma situação semelhante de briga entre seus alunos. Ou pode rejeitar esse modo de agir e nunca o imitar (anti-modelo). Isso porque a intervenção que o seu professor teve na sua infância/adolescência o marcou, de modo que essa relação professor/aluno ganhou um significado importante para sua vida. 
O livro "O professor de educação fisica e a construção do saber", de BORGES (1998), relata a ocorrência desses saberes da experiência. Ao analisar a história de vida de dois professores de Educação Física e relacioná-la às suas atuaçōes docentes, a autora observou que o conteúdo predominantemente nas aulas de um dos professores era o esporte; além disso, havia uma forte separação de sexo ${ }^{1}$ entre seus alunos. Após diversas análises, a autora concluiu que esses aspectos prevalentes da aula desse professor também eram encontrados nas aulas de Educação Física das quais ele participou na sua infância.

Esses saberes são transmitidos e apropriados fora da escola. Por exemplo, uma criança sempre brincou descalça, seja na rua ou em casa, e seus pais nunca a recriminaram por isso. Quando essa criança vier a ser um professor e deparar-se com um de seus alunos tirando o calçado para participar de suas atividades, isso poderá não lhe implicar em um ato de negação. $\mathrm{O}$ professor poderá resgatar, mesmo que em seu inconsciente, a relação de alegria, prazer e descobertas que uma criança vivencia ao brincar com os pés descalços.

Essa construção de saberes, como os exemplos acima, não foi adquirida de maneira formal ou sistematizada, uma vez que "há aprendizagem sem ensino direcionado para tal" e, além disso, "há formas de ser e de agir, ainda não sistematicamente racionalizadas, que levam à aprendizagem" (VIEIRA, 1999, p.10), e que dão a impressão de que uma parte de todo esse processo consiste em um "não saber".

Portanto, concordando com BORGES (1998), reforçamos a ideia de que o exercício da profissão docente não é neutro, ele é repleto de crenças, saberes e concepçóes que foram/são apropriadas culturalmente por meio de relações sociais, porém são reconstruídas individualmente e/ou coletivamente pelos docentes.

\section{Período acadêmico}

O período acadêmico corresponde ao início da formação sistematizada. Nessa fase, o futuro professor adquire grande parte dos conhecimentos específicos, entretanto, "não se deve pretender que a formação inicial ofereça produtos acabados, encarando-a antes como a primeira fase de um longo e diferenciado processo de desenvolvimento profissional" (MARCELO-GARCIA, 1995, p.55).

Ao basearmo-nos em Marcelo-Garcia (1995), Pérez-Gómez (1995), Ramos (2005) e Zeichner (1995), evidenciamos que grande parte dos conhecimentos que o aluno universitário (futuro professor) adquire é por meio de uma transmissão que raramente envolve uma reflexão mais aprofundada de tais conhecimentos. A formação de professores tem ocorrido, em sua grande maioria, por meio da perspectiva da racionalidade técnica "cuja concepção central entende que a atividade profissional consiste na solução instrumental de um problema através da aplicação de uma teoria científica ou técnica" (RAmOs, 2005). Tal visão apresenta-se de forma dicotômica entre teoria e prática, com subjugação da segunda à primeira.

Não pretendemos, de modo algum, desprezar a teoria. Simplesmente almejamos destacar que a prática pedagógica é repleta de incertezas e situaçōes problemáticas que não apresentam soluções pré-resolvidas.

Deste modo, consideramos que a teoria também é importante e vamos ao encontro de MiZUKAMI, REALI, Reyes, Martucci, Lima, Tancredi e Mello (2002, p.59) quando afirmam que a formação de professores sob uma orientação reflexiva deveria "contemplar claramente o conteúdo, os processos e as atitudes valoradas na prática reflexiva”. As autoras salientam, ainda, que "considerar a reflexão como 'orientação conceitual' seria, sob tais óticas, mais pertinente e apropriado à compreensão da natureza de processos de aprendizagem profissional" (p.61) e, portanto, evitar-se-ia que os conteúdos da reflexão tornem-se imateriais ou equivocados.

Assim, na nossa concepção, consideramos importante a formação de professores que se fundamenta na perspectiva da racionalidade prática (MARCELOGARCia, 1995; Pérez-GÓMEZ, 1995; SCHÖN, 1995; ZEICHNER, 1995). Esta compreende a prática como um campo de produção de saberes. A formação baseada nessa perspectiva forma profissionais reflexivos. Tais profissionais, por meio de suas reflexões, podem ser considerados produtores de conhecimento, uma vez que conseguem realizar uma leitura da própria prática, resgatando seus conhecimentos cotidianos e científicos, suas crenças e valores para resolver, naquele instante, situações-problema.

Desta forma, além da reflexão que ocorre durante a atuação docente é importante também aquela que acontece a "posteriori” à prática, uma vez que permite aos professores analisar e avaliar suas próprias ações de modo mais elaborado (com os conhecimentos teóricos e com o auxílio de seus saberes construídos com a prática docente), a fim de reestruturá-las e reconstruí-las de modo a proporcionar uma atuação mais adequada nas próximas intervençōes.

Segundo Betti e Betтi (1996), ao direcionarmos a formação docente voltada para a perspectiva da racionalidade prática, as situações tidas como práticas deveriam abranger todas as disciplinas do currículo acadêmico, além de serem incorporadas desde os primeiros anos de formação. 
Entretanto, embora já existam currículos baseados na perspectiva da racionalidade prática, ainda encontramos poucas estruturas e/ou disciplinas voltadas a essa perspectiva, geralmente práticas de ensino e estágios, e que, por vezes, acabam se desenvolvendo nos últimos anos da formação acadêmica, reforçando a ideia da prática como mera aplicação de teorias aprendidas em momentos anteriores.

Tratando, particularmente, dos estágios, consideramos estes como um grande campo de conhecimentos (Ramos, 2002). Por meio deles, ao mesmo tempo que os alunos aprendem com os profissionais mais experientes, eles podem levar os novos conhecimentos acadêmicos para os locais onde estão estagiando e, desta forma, exercendo uma certa mediação em tal processo.

Mediante o exposto, acreditamos que numa formação acadêmica voltada para a perspectiva da racionalidade prática, com estágios bem estruturados e na perspectiva do ensino reflexivo, a temática sobre histórias de vida de professores pode ganhar espaço e levantar informações úteis e importantes a serem discutidas durante a formação inicial. Como exemplo, citamos BetTi e MizuKami (1997) que, ao investigarem a história de vida e trajetória de uma professora de Educação Física, indicaram pontos que interferem na vida profissional e que merecem ser discutidos na formação de professores, como: a escolha vocativa da profissão, o prazer em dar aula, a influência da família, o reconhecimento de outros profissionais, as condições de infra-estrutura escolar, entre outros. Assim, acreditamos que uma formação acadêmica estruturada dentro da perspectiva apontada pode contribuir de forma sólida e consciente com a construção significativa de saberes docentes.

\section{Atuação profissional}

Compreende o período em que o professor está em pleno exercício da profissão. É uma fase em que os saberes da experiência incorporam grande significado. De acordo com VieIRA (1999), além da construção prévia de um determinado perfil de professor, devido a socialização pela qual ele passou ao longo da vida, há competências que só são apropriadas com o contato com o própria realidade de atuação.

Além disso, esse período que compreende a atuação profissional do professor apresenta um grande entrelaçamento de saberes, pois recorre àqueles transmitidos culturalmente durante a infância e adolescência, àqueles apropriados por meio do ensino superior e àqueles que estão ganhando significado com a própria prática docente.
Uma das características da profissionalidade docente é o significado pessoal que o professor atribui a sua atuação profissional. DAOLIO (1994, p.16) olha para os professores de Educação Física "como um grupo constituído por seres sociais, buscando e fazendo de sua atuação profissional cotidiana o sentido para suas vidas". Complementa afirmando que os professores refletem nas suas atuações docentes "determinados valores segundo a forma como foram educados, como foram preparados profissionalmente, segundo a escola em que trabalham etc." (p.17). A formação docente é, pois, contínua, o quer dizer que, enquanto o professor estiver em atividade, novos saberes vão se construindo. Assim, ele se renova e se (trans)forma a todo momento, mediante o seu convívio social.

A construção e apropriação dos saberes das experiências docentes apresentam significados diferentes de acordo com uma série de fatores: idade do professor, o tempo que ele atua (docente novato ou mais experiente), ou objetivos profissionais e pessoais que ele se coloca (Амоrim Filho, 2007). Pensando em tais fatores HUbERMAN (1995) os organizou em um ciclo de vida profissional dos professores, contendo as características mais comuns dos docentes, mediante o tempo que eles atuam. As fases que compreendem esses ciclos são: a entrada na carreira, a fase de estabilização, a fase de diversificação, a fase em que o professor põe-se em questão, a fase de serenidade $e$ distanciamento afetivo, a fase de conservantismo $e$ lamentaçōes, e a fase de desinvestimento da carreira.

Claro que tais fases não são estanques e nem devem ser compreendidas como uma camisa de força, mas são representativas e reveladoras dos vários momentos vivenciados pela maioria dos docentes. De acordo com a fase em que eles se encontram no ciclo profissional, os professores, em sua maioria, apresentam anseios diferentes e, portanto, construção de saberes também diferentes.

Podemos citar como exemplo a tese de doutorado de FerReIra (2005). A autora atuou como mentora em um programa de iniciação à docência, onde a fase de entrada na carreira docente é repleta de inseguranças e incertezas. Trabalhou de modo a auxiliar dois professores de educação física no primeiro ano de carreira a lidar com os aspectos da cultura escolar e que podem ser traumáticos a eles, como a relação com os alunos, diretoria e demais professores da escola. A autora concluiu que o programa de mentoria para iniciantes da carreira docente mostra-se muito importante para que os recém professores superem tais dificuldades.

Nessa seção, em que tratamos dos aspectos relacionados à atuação prática e dos saberes do professor, consideramos importante ressaltar que o docente 
tanto apropria-se de saberes e culturas, quanto os transmite e/ou os produz junto aos alunos/outros professores/direção da escola.

DAOLIO (1994, p.39-40) deixa isso evidente quando relata que "o homem, por meio do seu corpo, vai assimilando e se apropriando de valores, normas e costumes sociais, num processo de inCORPOração (a palavra é significativa)"; referindo-se ainda à relação corpo/cultura, afirma que "mais do que um aprendizado intelectual, o indivíduo adquire um conteúdo cultural, que se instala no seu corpo, no conjunto de suas expressões. Em outros termos, o homem aprende a cultura por meio do seu corpo" e entendemos que também ensina cultura por meio do seu corpo.

Considerando as turmas mistas (meninos e meninas) na Educação Física escolar, ao ministrar aulas de dança apenas para as meninas o professor, além de ensinar os movimentos, conceitos e técnicas desse conteúdo, poderá transmitir ou reforçar um preconceito de que só as meninas podem dançar. Ao ensinar futebol somente aos meninos, o docente, além de ensinar conceitos, táticas e técnicas, estará transmitindo e perpetuando os preconceitos existentes em nossa sociedade machista (AMORIM FILHO, 2007).

Tudo isso acontece porque todo ser humano utiliza seu corpo para assimilar e transmitir, aprender e ensinar culturas.

Nesse momento em que tratamos da construção dos saberes docentes, trazemos à memória alguns aspectos já caracterizados anteriormente como professores reflexivos, racionalidade prática, conhecimento tácito, relação aluno-estagiário/professor como pontos fundamentais e determinantes para uma valorização dos saberes da experiência.

\section{Processo metodológico}

A pesquisa aqui apresentada é de natureza qualitativa, ou seja, é concebida como "uma trajetória circular em torno do que se deseja compreender, não se preocupando única e/ou aprioristicamente com princípios, leis e generalizações, mas voltando o olhar à qualidade (...)" (GARNICA, 1997, p.111).

Assim, os instrumentos de coleta de informaçôes e a análise e interpretação dos dados não foram orientados com base em valores numéricos, mas servimo-nos do caráter descritivo que envolve as pesquisas de corte qualitativo.

$\mathrm{O}$ instrumento utilizado durante a coleta dos dados foi a entrevista semi-estruturada, uma vez que
PéREZ-GómEZ (1995), ressaltando a importância do conhecimento tácito, afirma que ele se insere na vida de qualquer docente prático, assim como a vida dos professores depende de tal conhecimento.

Assim, é na prática docente que o conhecimento tácito, aquele que não pode ser ensinado, mas que pode ser aprendido com as experiências (PÉREZGÓMEZ, 1995), eleva-se em sua importância. Desse modo, é preciso dar uma maior relevância ao saberes advindos da experiência, assim como é preciso tratá-los de maneira igualmente significativa aos conhecimentos acadêmicos.

Portanto, com esta base (infância/adolescência, período acadêmico e atuação profissional) que abordaremos a temática das histórias de vida docentes, ressaltando que as decisões relativas à escolha da profissão, a direção que é dada à carreira, assim como perspectivas futuras, entre outros, "poderiam ser convenientemente estudados e compreendidos melhor se, além dos aspectos eminentemente profissionais, atentássemos também a pessoa que é o professor" (Santos, Bracht \& Almeida, 2009, p.159-60). Deste modo, os professores devem ser compreendidos como "pessoas e profissionais cujas vidas e trabalhos se modelam mutuamente. Silenciar a relação entre ambos, de modo contrário, não nos levará muito longe na compreensão do processo de formação profissional" (p.160).

Nesta perspectiva e considerando a carência de estudos que tratam de tal temática, as histórias de vida de professores necessitam ser abordadas, investigadas e dialogadas durante a formação inicial, uma vez que elas carregam informações importantes para os futuros profissionais da carreira docente.

ela garante a obtenção de informações e proporciona mais liberdade para o entrevistado abordar aspectos considerados importantes por ele e que também podem vir a ser importantes para o estudo; assim, a entrevista ganha maior flexibilidade (NEGRINE, 1999, p.75).

Optamos por utilizar um aparelho gravador para auxiliar a coleta de dados deste estudo e um roteiro com perguntas, predominantemente abertas a fim de guiarmo-nos durante a entrevista, conforme sugerem LÜDKE e ANDRÉ (1986).

Além disso, ao assumir uma responsabilidade ética com as professoras entrevistadas, nós esclarecemos o objetivo do estudo, os procedimentos metodológicos 
e a importância da participação das voluntárias. $\mathrm{O}$ anonimato das docentes, assim como das escolas onde elas lecionam, foram garantidos e após elas assinarem um Termo de Consentimento Livre e Esclarecido, autorizando e concordando com a pesquisa, iniciamos a entrevista. Dessa forma, procuramos destacar a importância dos relatos oferecidos pelas depoentes, de modo que essa pesquisa fosse vista como significativa para todas as pessoas envolvidas.

Portanto, com intuito de compreender a profissão e os processos de profissionalização docente foi que abordamos tais temáticas, a partir da ótica dos próprios sujeitos nela envolvidos, no caso deste estudo, duas professoras de Educação Física escolar, utilizando, então, as histórias de vida como perspectiva metodológica com a realização de entrevistas e sob a perspectiva do referencial teórico de HuBERMAN (1995).
Optamos por entrevistar duas professoras de Educação Física - uma experiente (PE) e outra novata $(\mathrm{PN})$.

A PE leciona há quase 30 anos, passou por três Instituições de Ensino Superior até concluir sua formação inicial e hoje leciona para alunos do Ensino Fundamental e Médio em uma escola da rede pública, localizada na região central da cidade de São Carlos - SP.

A PN graduou-se no ano de 2005, na UFSCar, e ingressou no curso de Filosofia dessa mesma instituição no ano de 2007. Atualmente, ela trabalha como professora de Educação Física na rede pública de uma escola localizada na periferia de São Carlos - SP há, aproximadamente, um ano e meio.

Por fim, salientamos que nos excertos correspondentes aos depoimentos das professoras, mantivemos o discurso genuíno das mesmas.

\section{Apresentação, análise e discussão dos dados}

Após realizadas as entrevistas semi-estruturadas com as professoras organizamos as categorias de análise, que abarcam as informações que mais se repetiram durante o discurso das docentes, além daquelas que julgamos como sendo também importantes para compor essa análise, mesmo que não tenham sido citadas com tanta frequência, ou seja, as informações que podem desvelar mensagens implícitas e temas sistematicamente "silenciados" (LÜDKE \& ANDRÉ, 1986, p.48).

Mediante esse prisma, as categorias criadas foram: categoria I: A infância e os possíveis reflexos na atuação profissional; categoria II: Visão de curso/ universidade; categoria III: Dificuldades/reflexôes sobre a vida docente.

Ressaltamos que, embora haja a separação das informações em categorias, não podemos esquecer de relacioná-las com um aspecto global e que integra o objetivo desse estudo: as histórias de vida e a construção dos saberes docentes.

\section{Categoria I: a infância e os possíveis reflexos na atuação profissional}

Nesta categoria apresentamos as mençôes feitas pelas professora experiente (PE) e professora novata (PN) durante as entrevistas acerca do período correspondente às suas respectivas infâncias e correlacionamos possíveis reflexos/influências dessa época com as suas atuações como professoras de Educação Física escolar.

Segundo a PE, a sua infância foi marcada pelos momentos de brincadeiras e principalmente pela educação rígida dos pais que, não lhes davam muita liberdade.

Já as brincadeiras de rua como subir em árvores, pega-pega, esconde-esconde, jogos com bola, pular corda e peteca foram relembradas pela $\mathrm{PE}$ com grande satisfação e alegria. Talvez a perda, o esquecimento ou a substituição dessas brincadeiras populares pelo entretenimento oferecido pelas novas tecnologias de comunicação, entre elas a televisão, os videogames e principalmente a internet, possam ser uma das causas da aversão da docente a esses mecanismos de informática, uma vez que se auto-denomina como uma pessoa anti-tecnologia e afirma que não tem paciência de ficar horas em frente a um computador.

Ressaltamos, mais uma vez, que esses sentimentos de prazer, medo e alegria que ocorreram no período da infância da PE foram construindo ao longo do tempo os seus valores, as suas crenças e sua identidade. Segundo Goodson (1995), quando um professor leciona em um ambiente sócio-cultural semelhante ao que ele foi criado e educado, o seu processo de ensino pode tornar-se mais rico e facilitado (grifos nossos).

Percebemos, durante o discurso dessa docente, que as satisfações proporcionadas pelas brincadeiras da sua infância podem ter se refletido em uma identificação em lecionar aulas de Educação Física para crianças. 
Por outro lado, a educação rígida que a $\mathrm{PE}$ recebeu dos pais pode ter ocasionado o descontentamento que ela sente hoje ao ministrar aulas para adolescentes do Ensino Médio. A dificuldade em lidar com os alunos dessa faixa etária e, segundo ela, com a falta de educação, rebeldia, falta de respeito e organização, faz com que se sinta desanimada com o seu trabalho.

Meu Deus! Eu nem gosto de falar do Ensino Médio não! Ensino Médio pra mim me deixa muito de baixo astral! Porque eu não consigo! (...) eles não querem saber de nada, é muita farra, muita falta de respeito, né! (...) Sempre que eu posso eu escolho de primeiro ano até sétima série, não sou muito adepta ao Ensino Médio não! (PE).

Esse descontentamento não é reflexo único e exclusivo da educação rígida que a $\mathrm{PE}$ recebeu. Outros aspectos como: formação acadêmica e o processo de desinvestimento profissional, que pode ocorrer no final da carreira docente (HuBERMAN, 1995) podem, também, refletir nesse sentimento de "baixo astral", relatado pela professora. Entretanto, essas outras considerações serão abordadas nas próximas categorias de análise.

Os docentes, antes de tornarem-se profissionais, também já foram alunos. Portanto, é importante mencionar tal período, uma vez que, tratamos nesta categoria, a respeito da infância e os possíveis reflexos na atuação profissional.

A PE se recorda com contentamento da sua Educação Física escolar e de seus ex-professores e revela que o entusiasmo em cursar uma faculdade de Educação Física começou dentro da escola.

Uma característica significativa da Educação Física escolar dessa docente mais experiente, foi a função biologicista que, geralmente, traz em sua essência alguns aspectos como a busca de um corpo forte e saudável (Alves, 2006). A PE afirma que, na sua época de criança, os professores davam noção do que é Educação Física, uma vez que ministravam conteúdos relativos aos sistemas vascular e músculoesquelético e que, mesmo apresentando dificuldades, tenta transpor esses diversos aspectos/conteúdos do seu período como aluna para as aulas que ela leciona nas escolas. Outro aspecto que circundou as aulas de Educação Física da PE foi a esportivização como conteúdo hegemônico (BETTI, 1995), fundamentado com as já conhecidas "turmas de treinamento":

Eu treinava vôlei, handebol e basquete... futebol na minha época, mulher não participava. Só prá assistir, tanto que até hoje eu ainda não sei nada! (risada). Pôr o pé numa bola?... putz! Não sai nada, né! (risada) (PE).
Antes de discorrer sobre a temática da esportivização da Educação Física escolar, chamamos a atenção para a sua separação por sexo nas aulas. A PE já havia chamado a atenção para a falta de liberdade da mulher, portanto, gostaríamos de ressaltar que essa discriminação está enraizada pela atribuição de papéis e imposições sociais que são construídas / transmitidas culturalmente.

DaOlio (1994) já ressaltava esse assunto, enfatizando que o homem tanto apreende quanto transmite cultura por meio do seu corpo e dos seus movimentos. Segundo o autor, quando o menino ganha uma bola como seu primeiro presente e passa a ser estimulado a iniciar os primeiros chutes, também se inicia um processo de transmissão cultural, já que as meninas além de não serem estimuladas, são impedidas de brincar com bola utilizando os pés.

Entretanto, não encontramos relação entre esta Educação Física escolar que enfatiza a separação pelo sexo dos alunos, típico da infância da docente, e a sua atuação profissional. Talvez, a experiência da própria prática docente e os cursos de atualização pelos quais passou, tenham sido importantes para que esses reflexos da sua infância não fossem transportados para os dias atuais.

Por outro lado, a questão da esportivização na Educação Física parece fazer parte até hoje das aulas ministradas pela $\mathrm{PE}$. A docente relatou o sentimento de insatisfação ao comparar a Educação Física e os alunos do seu período de escolar com o cotidiano atual das suas aulas. A falta da perfeição técnica dos movimentos esportivos por parte dos seus alunos causa um sentimento de frustração e mágoa para a professora. Esse descontentamento é gerado pelo fato de que tanto a sociedade quanto a Educação Física passaram por um processo de transformação, em que apesar do esporte continuar prevalecendo nas aulas a sua perfeita execução passou a não ser cobrada como antigamente e essa mudança pode não ter sido entendida/aceita pela docente.

Neste momento, trazemos para a discussão dessa categoria - A infância e os possiveis reflexos na atuação profissional - os relatos da docente novata.

A infância da PN aconteceu na cidade de São Paulo - SP e foi marcada pelas grandes preocupações dos pais devido aos "perigos" da capital.

As brincadeiras foram apontadas tanto pela professora experiente quanto pela professora que está no início da carreira como sendo uma característica marcante do período correspondente à infância. Deste modo, retomamos o conceito de que 
o professor reflete, em muitas de suas ações docentes, as crenças e valores que ganharam significados enquanto o seu papel de filho, aluno e cidadão (SILVA, 2000). Portanto, salientamos a importância e necessidade de haver o respeito e orientação (quando for preciso) a todo e qualquer tipo de emoção que vislumbra o ato de brincar da criança, pois muito de sua identidade está sendo gerada nesse momento.

Entretanto, a experiência como aluna foi o aspecto da infância da $\mathrm{PN}$ que, segundo ela, mais influencia a sua prática docente nos dias de hoje. Segundo TARDiF e RAYMOnd (2000, p.219), "os saberes experienciais do professor de profissão, longe de serem baseados unicamente no trabalho em sala de aula, decorreriam, em grande parte, de preocupaçóes do ensino e da aprendizagem herdadas da história escolar" (grifo nosso).

Durante a entrevista, quando solicitamos à PN que comentasse sobre a Educação Física escolar e o seu papel como aluna, obtivemos de imediato um discurso detalhado, cercado por sentimentos de trauma e medo. A docente relatou o ambiente incerto e imprevisível das aulas de Educação Física enquanto discente. Alunos com diversas faixas etárias, em diferentes níveis de aprendizagem, com anseios e expectativas incomuns, obrigados a realizar a mesma atividade e, ainda, sem orientação do profissional. Isso fez com a PN carregasse consigo a aversão à prática de diversas modalidades esportivas, principalmente do voleibol, entretanto, esse sentimento de medo tem raízes e origens na situação em que ela foi posta enquanto aluna, ao invés do conteúdo propriamente dito. Agora, deveríamos refletir: quantas crianças, jovens e adultos devem rejeitar a prática de atividades físicas pelas frustraçōes causadas durante as aulas de Educação Física escolar? Chamamos a atenção a esse ponto, pois sabemos que a situação descrita acima faz parte da realidade da escola e da Educação Física escolar.

Este medo relatado pela docente, assim como "o sucesso ou insucesso de certas experiências" (NóvOA, 1995, p.16) marcam a postura pedagógica da PN, ou seja, antes de ser professora, ela foi aluna e, como tal, aprendeu "a acreditar em algumas ideias e valores", também construiu "as suas próprias, acerca da escola, do ensino, da aprendizagem e sobre como ser professor e como ensinar, sobre fazer e sobre como saber fazer" (Silva, 2000, p.34).

A PN relatou até algumas artimanhas que ela utilizava para escapar das aulas de Educação Física, como pedir para a sua mãe levar um atestado que comprovasse que ela realizava aulas de natação no mesmo horário da Educação Física escolar, conseguindo assim dispensa.
No caso da PN, o atestado para dispensa das aulas de Educação Física reflete o medo e constrangimento pelo qual a docente passava nas situações descritas acima, sendo facilitado pelo período contrário dessa disciplina em relação às outras.

Tais atestados são um ponto agravante em nossa sociedade. Segundo Darido, Galvão, Ferreira e Fiorin (1999), em um estudo realizado com 30 professores do interior do Estado de São Paulo, os grandes índices de dispensa das aulas de Educação Física aparecem, geralmente, quando essa disciplina é ministrada no período contrário ao das demais. Isso acontece pela dificuldade de transporte ou, também, por existir muitos alunos que trabalham no período oposto ao das aulas. Ainda, outro aspecto que acarreta o aumento dos pedidos de dispensas são as aulas consideradas monótonas e desinteressantes para os alunos.

Entretanto, as próprias experiências extra-escolares, como as aulas de natação e as brincadeiras no quintal de casa, acabaram por conduzir a $\mathrm{PN}$ em prestar vestibular para Educação Física. A docente relatou que gostaria de ser professora de natação para proporcionar às outras pessoas o prazer que ela sentia nadando.

Desta forma, concordando com MorTA (1995, p.116), percebemos que "só uma história de vida põe em evidência o modo como cada pessoa mobiliza os seus conhecimentos, os seus valores, as suas energias, para ir dando forma à identidade, num diálogo com os seus contextos".

Assim, as experiências negativas que a PN teve na sua Educação Física escolar serviram para que ela, em suas reflexões na e sobre a prática docente, não reproduzisse o mesmo com os seus alunos. Dessa forma, ela diz tomar cuidado na hora em que algum aluno precisa ser exposto, para não gerar nenhum tipo de constrangimento ou exclusão. Afirma, ainda, que quando alguém não quer jogar ou realizar as atividades propostas ela sempre tenta incentivar, motivar e principalmente orientar os alunos durante a prática, para que no futuro, ou em outras instâncias de suas vidas, aquele dia não lhes proporcionem outras frustrações.

Durante o contato que tivemos com as PE e PN para elaboração deste estudo, percebemos que, durante as entrevistas, elas puderam realizar reflexões e identificar influências acerca do período em que eram crianças e a suas práticas docentes. Logo, a escola e a família foram os pontos mais destacados nos depoimentos das duas professoras quando tratamos do período referente às suas infâncias, entretanto, a PN deu maior ênfase ao primeiro tema e a PE ao segundo. 
A seguir tratamos a respeito das experiências e visōes que as docentes apresentam sobre a universidade e o curso superior de Educação Física no qual elas se formaram.

\section{Categoria II: visão de curso/universidade}

Quando perguntamos às docentes sobre as suas perspectivas acerca do curso de Educação Física antes do ingresso no Ensino Superior, obtivemos respostas semelhantes. Nos dois casos, as professoras imaginavam uma graduação voltada exclusivamente às modalidades esportivas. A PE relatou a sua surpresa ao deparar-se com assuntos relacionados à psicologia ou legislação, por exemplo. A PN também esperava estudar somente esportes como a natação ou o voleibol.

Essa visão pode ser reflexo das experiências das docentes enquanto alunas escolares, dos conceitos apresentados pela mídia e demais meios de comunicação ou, ainda, das construções sociais e culturais sobre Educação Física, a qual gera a própria falta de caracterização da área, uma vez que a sociedade passa a enxergá-la como algo eminentemente prático em oposição ao teórico. Além disso, essa imagem que as professoras apresentam da Educação Física, muitas vezes, acaba sendo reforçada dentro do próprio curso de formação de professores. Embora alguns cursos estejam estruturados pela alta exigência de produção de conhecimentos teóricos e de suas publicaçōes, ao nosso ver, a maioria dos cursos de Educação Física ainda dá ênfase, prioritariamente, às disciplinas baseadas em atividades práticas da sua estrutura curricular. Assim, a visão distorcida que os graduandos têm antes de ingressarem na universidade acaba fortalecida pelo curso cercado de atividades relacionadas aos esportes, jogos, danças, entre outros (TANI, 1995).

Os depoimentos das docentes também vão ao encontro das afirmaçōes de BETTI (1996, p.75-6) quando afirma que, nos dias atuais, a Educação Física é confundida com as aulas de hidroginástica, musculação, esporte, dança... .A escola, em particular, ficou restrita à prática de esportes e, no meio acadêmico, sua terminologia é, por muitas vezes, substituída pela nomenclatura "Ciências do Esporte". No caso da professora mais experiente, essa visão biológica e esportivista da Educação Física pode ter grande relação com o período em que ela cursou a sua graduação (década de 70), uma vez que, a pedagogia tecnicista norteava os cursos de formação daquela época. Assim, os mesmos eram fundamentados nos movimentos ginásticos e técnicas esportivas, o que justifica as suas expectativas.
Já com relação à $\mathrm{PN}$, a própria docente relatou que a sua visão de esporte relacionado à Educação Física tem fins na própria falta de caracterização da área, na sua experiência enquanto aluna e na veiculação do esporte espetáculo propagado pela mídia.

Bетті (1995), em um estudo intitulado "Esporte na escola: mas é só isso, professor?”, já chamava a atenção sobre o conteúdo esporte sendo tratado de maneira hegemônica nas aulas de Educação Física escolar. A autora levanta algumas questões para esclarecer o motivo pelo qual outros conteúdos não são abordados, entre eles: falta de espaço físico, material e motivação para os professores; comodismo; falta de aceitação pela sociedade ou, ainda, os professores podem desenvolver somente os conteúdos (no caso, esportes), com os quais têm maior afinidade. Entretanto, a falta de conteúdos diversificados faz com que os alunos apropriem-se de uma visão distorcida e descaracterizada do que seja realmente a Educação Física em seu aspecto geral e como curso acadêmico.

As professoras entrevistadas apresentam, hoje, visões diferenciadas sobre o curso de Educação Física e universidade de uma maneira geral, atribuindo significados e importâncias diferentes ao meio acadêmico.

A PE passou por três Instituições de Ensino Superior até terminar a sua graduação. Ela considerou a sua formação fraca em qualidade e insuficiente para o exercício da profissão. Talvez por essa razão, quando solicitada a discorrer sobre a sua formação acadêmica, a docente respondia sucintamente, sem demonstrar muito interesse.

Já a PN atribui ao seu período acadêmico a responsabilidade pela grande transformação, tanto no seu lado pessoal quanto profissional. Afirma que se tornou uma pessoa mais crítica devido ao curso de Educação Física e também a toda a vida acadêmica. As relaçóes com pessoas de outros cursos e participação como integrante do centro acadêmico, proporcionaram uma das coisas que ela considera como mais relevantes: uma visão política de mundo. Assim, a docente optou em filiar-se e militar por um determinado partido político. Tais experiências dentro da universidade estão refletidas na sua prática pedagógica, de modo que a PN discute com os seus alunos a importância deles tomarem opinião, se organizarem, formarem o grêmio estudantil da escola, reivindicarem o que desejam para a escola, além de questionar os professores e a direção.

Talvez, por esta docente ser recém-formada em Educação Física e por continuar como aluna universitária, já que ingressou no curso de Filosofia no ano de 2007 , o papel da universidade seja ainda muito 
forte para ela, o que não acontece com a PE, que é formada há 30 anos e que passou por três Instituições de Ensino Superior diferentes, o que pode ter contribuído para que ela não criasse vínculos mais sólidos.

Contudo, ambas as professoras apresentaram em seus depoimentos as "lacunas" encontradas no curso acadêmico. A docente experiente afirma que os seus professores de universidade não ensinavam como se deve ministrar as aulas e o que fazer diante dos alunos, por exemplo. Assim, quando ela se deparou com as turmas, apenas lembrava-se de alguns movimentos que seus professores de graduação executavam e tentava imitá-los.

Temos a impressão que a $\mathrm{PE}$ almejava receber na universidade conhecimentos operacionais, que pudessem ser utilizados na sua prática pedagógica. Talvez, a não compreensão de que no período acadêmico são construídas apenas partes dos saberes docentes tenha provocado essa sensação de que não aprendeu nada ou quase nada durante o curso de graduação (GUARNIERI, 2000).

Da mesma forma, a PN apresentou fatores que, na sua opinião, são tratados de forma alienante dentro do curso de educação física, como a simulação de uma aula prática escolar (ao invés de vivenciá-la no próprio ambiente escolar) e as tendências pedagógicas que vão de encontro à realidade escolar, pois não refletem o dia-a-dia da escola. Segundo PN, as simulações de aulas escolares, assim como as tendências pedagógicas aprendidas no curso de formação inicial diferem-se muito da realidade encontrada na escola, deste modo, ela interpreta negativamente esses momentos que compreenderam sua formação acadêmica.

Por não ser objetivo deste estudo, não queremos aqui simplesmente concordar ou discordar da opiniāo da PN, porém, entendemos que em alguns momentos da formação inicial as simulações são preparatórias e importantes no processo formativo do futuro professor. Da mesma forma, sabemos que muitas das chamadas "tendências pedagógicas" brasileiras foram elaboradas a partir de situações provenientes de observações ou mesmo de intervençôes concretas. Contudo, devemos respeitar a maneira que a PN entende, neste momento de sua trajetória profissional, alguns dos processos formativos pelos quais ela passou em seu curso de graduação.

Dando continuidade às histórias de vida das docentes e à construção dos seus saberes, na próxima categoria - Dificuldades/reflexôes sobre a vida docente - apresentamos aspectos e situações acerca das suas práticas pedagógicas em que vislumbramos considerável apreço, não perdendo o enfoque de que:
(...) um professor "não pensa somente com a cabeça", mas "com a vida", com o que foi, com o que viveu, com aquilo que acumulou em termos de experiência de vida, em termos de lastros de certezas. Em suma, ele pensa a partir de sua história de vida não somente intelectual, no sentido rigoroso do termo, mas também emocional, afetiva, pessoal e interpessoal (TARDIF $\&$ RAYMOND, 2000, p.235).

\section{Categoria III: \\ dificuldades/reflexões sobre a vida docente}

Nesta categoria, apresentamos as diversas situações relatadas pelas professoras entrevistadas a respeito de suas práticas docentes, assim como, as reflexões que têm sobre tais contextos.

Assim, a atuação profissional dos professores é envolvida por diversas relações, entre elas, com os alunos, demais professores, diretores, funcionários da escola, pais de alunos, comunidade, entre outras. Tais relaçóes podem auxiliar a prática docente como constituir uma barreira, uma dificuldade para a sua plena realização. Dentro desse contexto, o início da carreira docente pode apresentar as situações mais problemáticas, uma vez que o professor, por sua inexperiência, pode não saber lidar com tais circunstâncias. Entretanto, essas dificuldades tendem a diminuir com os anos de prática pedagógica e, consequentemente, pelo aumento da experiência e saberes docentes.

A PE relatou que apresentou diversas dificuldades no início da carreira, entretanto, sempre foi auxiliada por outros professores mais experientes. A PN, por outro lado, não mencionou o fato de receber auxílio de seus colegas de trabalho e, nem mesmo, destacou a relação com os seus pares. A respeito disso, já havia refletido CAVACO (1990, p.21): o "apoio dos mais velhos e experientes parece não ter hoje o valor quase absoluto que assumia outrora. Entre os mais novos tende-se a preferir as relações menos assimétricas, de cooperação (...)”. Talvez os professores em início de carreira, enraizados com a concepção de que possuem todo o conhecimento e conteúdo para lecionar e se relacionar com os alunos (uma vez que acabaram de sair da universidade), ou ainda, para não mostrarem/identificarem as dificuldades que têm, podem acabar rejeitando a ajuda dos docentes experientes e terminarem isolados dentro da escola.

Segundo Ferreira (2005) e Lima (2006), esse isolamento parte da própria instituição escolar que, geralmente, não acolhe e não dá suporte aos professores em início de carreira. 
Seguindo essa mesma linha de raciocínio, CAVACO (1990) afirma que muitos professores experientes não auxiliam os professores novatos nos seus momentos de inquietações e dificuldades, uma vez que entendem tais agruras como situações naturais e inevitáveis do universo escolar.

Entretanto, as situações incertas não acontecem somente com professores iniciantes, mas também estão presentes nas aulas de Educação Física da PE. Quando indagada a respeito dessa temática, a docente voltou a relatar a dificuldade que tem em lidar com a indisciplina dos alunos do Ensino Médio. Além disso, a professora abordou outro tema: a articulação com o imprevisto no dia-a-dia do fazer docente:

Tem coisa que você prepara e não dá certo, você aplica em uma escola e não dá certo, aí você tem que ter um raciocínio bem rápido e se virar né (...) (PE).

Já a docente novata diz sofrer com diversas situações como: falta de infra-estrutura da escola, turmas com número elevado de alunos, dificuldade em ministrar determinados conteúdos, o contexto social em que os alunos estão inseridos e problemas de indisciplina são as maiores dificuldades encontradas. Tais dificuldades também foram relatadas por LiMA (2006) em livro intitulado "Sobrevivências no início da docência”. Os relatos das professoras em início de carreira no estudo desta autora nos mostram que a solidão que as docentes sentem na escola, assim como as dificuldades que têm para manter a disciplina na sala de aula, lidar com os pais dos alunos ou com a aprendizagem destes alunos podem ser consideradas as principais dificuldades encontradas no início da carreira docente.

Entretanto, os professores de Educação Física em geral não podem se render às faltas de infra-estrutura ou materiais e assim, não lecionar; entendemos, como Bетті (1995), que os docentes além de exigir dos governantes condições mínimas de trabalho devem utilizar sua criatividade para improvisar materiais e ambientes para a prática de suas aulas.

GUARNIERI (2000) aponta que, ao se deparar com a situação real em que se dá a prática pedagógica, o professor iniciante pode rejeitar os conhecimentos que recebeu em sua formação acadêmica, uma vez que não consegue aplicá-los em sua prática. Assim sendo, ele pode acabar por adotar formas de agir semelhantes aos demais professores e gerar em si próprio sentimentos de conflito, desânimo e frustração.

Desta forma, fica evidente que a PN tem que sobreviver dentro da escola, numa luta constante para poder exercer as suas práticas pedagógicas. Esses impactos, segundo FERREIRA (2005), podem conduzir ao desencanto da profissão, o que acarretaria em uma atuação descompromissada, ou até mesmo ao abandono da carreira.

Entretanto, segundo Lima (2006) esta fase difícil do início da docência pode ser rompida quando as professoras descobrem a possibilidade de aprender com seus alunos e com seus pares, quando descobrem $o$ afeto e acolhimento dos alunos e quando percebem que a formação acadêmica (tanto as teorias aprendidas quanto a influência dos educadores que conheceram) pode auxiliá-las nos momentos de agruras.

CORSI (2006) também entende que a troca de experiências, principalmente entre os docentes, ajuda nessa construção de saberes que pode auxiliar, essencialmente, os professores novatos a resolver as dificuldades encontradas na árdua vida docente.

Outro aspecto interessante é que, mesmo com as dificuldades encontradas dentro da escola, as duas professoras consideram a prática docente como um grande campo para se adquirir e produzir conhecimentos. Tal aspecto ganha maior destaque no depoimento da PE. Muito provavelmente, por lecionar há quase 30 anos, os saberes da experiência são supervalorizados quando comparados com os adquiridos na universidade.

Desse modo, um ponto que nos chamou a atenção foi a respeito de como a PE reflete sobre uma aula que, eventualmente, não aconteceu de acordo com o seu planejamento e como ela lida com essa situação. Segundo a docente, ela observa os aspectos positivos e negativos durante a atividade; na sua casa, a posteriori, reflete e faz as alterações que julga necessárias e leciona novamente essa aula com as suas respectivas reformulações.

Esse depoimento nos revela que a PE utiliza os conceitos de reflexão na e sobre a ação docente, propostos por SCHÖN (1995), embora acreditamos que ela não teve contato com tal fundamentação teórica.

Por outro lado, a professora novata, que ainda não se desvinculou do meio acadêmico, atribuiu menores importâncias (mas não poucas) aos conhecimentos advindos da prática docente. Mesmo assim, ela respondeu de forma afirmativa, quando perguntamos se ainda se considerava, durante a prática docente, uma produtora de conhecimentos, entretanto, relatou não conseguir e/ou não ter tempo para registrar o que vem aprendendo, assim como fazia durante a sua graduação em Educação Física.

Talvez, a inexperiência somada a todas as dificuldades encontradas na escola não permita que a PN consiga analisar, de maneira mais aprofundada, a sua prática 
pedagógica. Segundo Corsi (2006) e ZabalZa (2004), o uso de um diário seria uma boa alternativa para tal situação, pois possibilitaria à $\mathrm{PN}$ refletir de forma organizada sobre as suas próprias ações e realizar as devidas reestruturaçōes na prática docente.

Nesse momento, julgamos importante reafirmar o que viemos tecendo nas entrelinhas desse trabalho: ao tentar entender a atuação dos profissionais é importante ouvir a voz dos professores, ou seja, valorizar as suas trajetórias de vida.

Por isso, vamos analisar as histórias de vida das docentes sob a luz do referencial teórico de HuberMAN (1995), contudo, não nos estenderemos por todas as fases contidas no ciclo proposto pelo autor, mas somente àquelas que parecem corresponder ao atual estágio das professoras.

A PN, ao nosso ver, parece encontrar-se na fase definida por Huberman (1995) como "A Entrada na Carreira". Segundo o autor, esse período é cercado pelo confronto de dois estágios: o de Sobrevivência e o de Descoberta. No primeiro, os professores percebem a distância entre a realidade encontrada na escola e os seus ideais, a dificuldade em transmitir os conhecimentos, dificuldades com as indisciplinas dos alunos, com a relação com os demais professores, com material didático inadequado, entre outros. Tais situaçôes problemáticas foram relatadas durante quase toda a entrevista com a professora iniciante, e isso fez com que atentássemos para esta fase.

Entretanto, após ou concomitantemente ao estágio de sobrevivência, pode ocorrer o estágio de descoberta. Nele o professor sente-se em uma situação de responsabilidade e isso pode the trazer um entusiasmo inicial e sentimento de experimentação e exaltação. Contudo, o estágio que se colocar sobre o outro pode deixar reflexos por todo o ciclo de vida profissional dos professores.

Por outro lado, PE parece encontrar-se na transição das duas últimas fases do ciclo, denominadas "Conservantismo e Lamentaçôes" e "O Desinvestimento" na carreira (HuBERMAN, 1995). Na primeira aparece a grande insatisfação dos professores com relação à situação do ensino presente e que pode acarretar num certo conservantismo, de modo que os docentes, ao compararem o passado (enraizados por suas crenças, valores e ambições) com o presente, glorificam o primeiro. É comum os professores mostrarem-se insatisfeitos com a instituição escolar, com o valor atribuído ao professor e com a mudança dos alunos com o passar das gerações. $\mathrm{O}$ excerto abaixo, extraído das falas da PE evidencia esta fase:

(...) o professor de Educação Física (na sua época como escolar) era valorizado! Tinha o mesmo valor que o professor de Matemática, o de Português! (PE).

Segundo Huberman (1995), o desinvestimento na carreira pode ocorrer em qualquer momento do ciclo de vida profissional docente, entretanto, essa tendência aumenta quando os professores chegam ao final de suas carreiras. Assim, eles começam a deixar suas ambições de lado, consagram mais tempo a si próprios e aos interesses exteriores à escola e apresentam maiores reflexões de suas vidas. Além disso, "em fim de carreira, supõe-se que as pessoas se desinvestem progressivamente, 'passam o testemunho' aos jovens, preparam a retirada, etc" (Huberman, 2005). A seguir, destacamos um excerto que elucida tais características da PE:

Espero que, se Deus quiser, o ano que vem eu tô aposentada do Estado, né, aí eu vou ficar só na Prefeitura. Quando eu aposentar no Estado no outro dia eu tô saindo, se Deus quiser! Dar lugar prá vocês que são jovens! (PE).

Esperamos ter mostrado nesta categoria de análise os assuntos abordados pelas professoras a respeito de suas práticas pedagógicas, assim como a importância em auxiliar os professores iniciantes diante das suas dificuldades encontradas na escola e também reforçar a ideia de que a prática e principalmente a reflexão sobre ela podem construir saberes que, somados aos conhecimentos científicos, poderão ser utilizados pelos docentes para reavaliar as suas atuações pedagógicas quando julgarem necessário.

\section{Considerações finais}

Em nosso estudo, os relatos feitos pelas PN e PE reafirmam as consideraçõos apresentadas nas pesquisas de Betti e Mizukami (1997), Santos, Bracht e AlmeiDA (2009) e Folle e Nascimento (2009). As docentes participantes desta pesquisa também discorreram sobre as influências de seus familiares nas suas atuaçōes profissionais, assim como, sobre as relações com seus pares; a indisciplina dos alunos; os problemas com a infra-estrutura escolar; a influência da Educação Física escolar na escolha das suas profissões; as dificuldades no início da carreira, entre outros aspectos, mostrando que tais temáticas são recorrentes no cotidiano escolar, nos fazendo, portanto, refletir sobre a importância de tratar desses assuntos na formação inicial de professores. 
As trajetórias de vida docentes, quando abordadas e analisadas como perspectiva metodológica, podem revelar aspectos relevantes para outros futuros professores. Por isso, concordando com NóvOA (1995, p.71), o que consideramos "surpreendente, se não francamente injusto, é que durante tanto tempo os investigadores tenham considerado as narrativas dos professores como dados irrelevantes".

Mediante esse prisma, ao dar voz às professoras entrevistadas neste estudo, percebemos possíveis influências do período correspondente à infância refletidas nas suas práticas pedagógicas. $\mathrm{O}$ trabalho sistematizado, altamente ordenado e as "atitudes um tanto severas" que compreendem a prática da professora experiente (PE), parecem ser reflexos da educação rígida e dos valores transmitidos pelos seus pais enquanto ela ainda era criança. Já a professora novata (PN), traz consigo uma sensação de mágoa muito forte relacionada às aulas de Educação Física vivenciadas na sua infância. A frustração em não conseguir praticar uma determinada modalidade esportiva, principalmente pela falta de orientação do professor, faz com que hoje ela se preocupe em instruir e incentivar os seus alunos a participarem das suas aulas na escola.

$\mathrm{O}$ período acadêmico deu início à apropriação dos conhecimentos específicos e formalizados para as futuras práticas docentes das professoras. Entretanto, $\mathrm{PE}$ talvez pelos vários anos de carreira, não atribuiu hoje significativa importância a tal período. Em contrapartida, $\mathrm{PN}$, que não se desvinculou totalmente da universidade, concede à Instituição de Ensino Superior grande responsabilidade pela sua visão de mundo e pelo seu crescimento no âmbito pessoal e profissional. Além dos conhecimentos acadêmico-científicos, a PN atribui grande valor às experiências relacionais não formais dentro da universidade, como a sua participação no centro acadêmico, o convívio com os alunos de cursos diferentes do seu, ou seja, as diversas relações que, de certa forma, englobam a "vida acadêmica".

Dando continuidade às construções dos saberes das docentes, chegamos às suas intervenções pedagógicas. A PN “sobrevive” às situaçôes problemáticas usualmente encontradas no início da carreira docente, como a dificuldade em lidar com a indisciplina dos alunos, em relacionar-se com seus pares, em dialogar o aprendido na universidade com a realidade escolar, entre outras, conforme também apontam os estudos de Huberman (1995), Guarnieri (2000), Ferreira (2005) e Lima (2006). Já PE, embora apresente relações com as fases de "Lamentações e Conservantismo" e "Desinvestimento" na carreira, consegue, na maioria das vezes, lidar com eficiência com as situações incertas encontradas na escola, uma vez que os anos de experiência contribuíram para que ela realize uma prática mais reflexiva.

Este estudo também pode ter ajudado as professoras experiente e novata a refletirem (durante as nossas entrevistas e conversas) sobre suas intervençōes docentes, e esperamos que este trabalho, assim como os outros que virão nessa mesma perspectiva, auxiliem outros professores em sua formação e também aqueles que já estão inseridos dentro do âmbito escolar.

Assim, não tivemos a intenção de julgar, qualificar ou dizer o que é certo ou errado na prática profissional das docentes analisadas. Procuramos elucidar que o professor de Educação Física que faz uma reflexão autobiográfica e estabelece uma analogia com a sua prática docente pode vir a ser um profissional melhor (АмORIM FiLHO, 2007), entendendo tanto o(s) porquê(s) dos seus atos e pensamentos como a importância do seu papel dentro da escola e, a partir daí, pode empreender alterações nas suas intervenções pedagógicas caso considere necessário.

\section{Abstract}

History of life and construction of knowledges of physical education teachers

Considering that the teacher's knowledge is built throughout several moments of the teachers' lives, both as students and as teachers, and that this subject should be approached more frequently during the initial years of their teaching education, the objective of this study was to analyze the courses of life of two teachers of Physical Education: an experienced teacher (ET), with almost 30 years of teaching experience, and a novice teacher (NT), with nearly one and a half years of teaching, of elementary and secondary schools in the city of São Carlos (São Paulo). We used a qualitative approach with a semistructured interviews. The analysis of the data led to the production of the following categories: 1) the childhood and the possible reflexes in the professional action, which presented the school and the 
relationship with the parents as the responsible parts for the transmission of values of what being a teacher is; 2) perspective of the course/university, eliciting the regard for the academic period in the view of both the ET and the NT; 3) difficulties/reflections about the teaching life, which revealed the obstacles found by NT in the beginning of her career, and also the knowledgeable ways adopted by ET when she dealt with the uncertainties that are involved in the teaching practice. In the view of that, we emphasize that the course of life of the teachers, when analyzed as a methodological perspective, can present important aspects for the prospect teachers, and they can also assist the teachers during their educational interventions because the teacher that associates and reflects his life course with his actions in the school can reconstruct his interventions and become a better professional.

UNITERMS: Teaching knowledge; Teaching education; Physical education.

\section{Referências}

ALVES, W.F. Sobre a formação profissional dos professores de educação física e as teorias do saber docente. Pensar a

Prática, Goiânia, v.9, n.2, p.313-30, 2006.

AMORIM FILHO, M.L. Estudo da trajetória de vida e construção dos saberes de duas professoras de educação física da cidade de São Carlos. 2007. 57p. Trabalho de Conclusão de Curso (Licenciatura) - Departamento de Educação Física e Motricidade Humana, Universidade Federal de São Carlos, São Carlos, 2007.

BETTI, I.C.R. Esporte na escola: mas é só isso, professor? Motriz, Rio Claro, v.1, n.1, p.25-31, 1995.

BETTI, I.C.R.; BETTI, M. Novas perspectivas na formação profissional em educação física. Motriz, Rio Claro, v.2, n.1, p.10-5, 1996.

BETTI, I.C.R.; MIZUKAMI, M.G.N. História de vida: trajetória de uma professora de educação física. Motriz, Rio Claro, v.3, n.2, p.108-15, 1997.

BETTI, M. Por uma teoria da prática. Motus Corporis, Rio de Janeiro, v.3, n.2, p.73-127, 1996.

BORGES, C.M.F.B. O professor de educação física e a construção do saber. Campinas: Papirus, 1998.

. Saberes docentes: diferentes tipologias e classificações de um campo de pesquisa. Educação \& Sociedade, Campinas, v.22, n.74, p.59-76, 2001.

CAVACO, M.H. Retrato do professor enquanto jovem. Revista Crítica de Ciências Sociais, Coimbra, n.29, p.121-39, 1990. CORSI, A.M. No início da docência. In: LIMA, E.F. (Org.). Sobrevivências no início da docência. Brasília: Líber Livro, 2006. p.53-65.

DAOLIO, J. Da cultura do corpo. 2. ed. Campinas: Papirus, 1994.

DARIDO, S.C.; GALVÃO, Z.; FERREIRA, L.A.; FIORIN, G. Educação física no ensino médio: reflexões e ações. Motriz, Rio Claro, v.5, n.2, p.138-45, 1999.

FERREIRA, L.A. O professor de educaçáo física no primeiro ano da carreira: análise da aprendizagem profissional a partir da promoção de um programa de iniciação à docência. 2005. 216 f. Tese (Doutorado em Educação) - Centro de Educação e Ciências Humanas, Universidade Federal de São Carlos, São Carlos, 2005.

FOLLE, A.; NASCIMENTO, J.V. Momentos marcantes da trajetória docente em educação física. Motriz, Rio Claro, v.15, n.1, p. 92-103, 2009.

GARNICA, A.V.M. Algumas notas sobre pesquisa qualitativa e fenomenologia. Interface: Comunicação, Saúde, Educação, Botucatu, v.1, n.1, p.109-22, 1997.

GOODSON, I.F. Dar voz ao professor: a's histórias de vida dos professores e o seu desenvolvimento profissional. In: NÓVOA, A. (Org.). Vida de professores. 2. ed. Porto: Porto Editora, 1995. p. 63-78.

GUARNIERI, M.R. (Org.). O início na carreira docente: pistas para o estudo para o trabalho do professor. In:

Aprendendo a ensinar: o caminho nada suave da docência. Campinas: Autores Associados, 2000. p.5-23.

HUBERMAN, M. O ciclo de vida profissional dos professores. In: NÓVOA, A. Vidas de professores. 2. ed. Porto: Porto Editora, 1995. p.31-62.

LIMA, E.F. (Org.). Sobrevivências no início da docência. Brasília: Líber Livro, 2006.

LÜDKE, M.; ANDRÉ, M.E.D.A. Pesquisa em educação: abordagens qualitativas. São Paulo: EPU, 1986. 
MARCELO-GARCIA, C. A formação de professores: novas perspectivas baseadas na investigação sobre o pensamento do professor. In: NÓVOA, A. (Org.). Os professores e a sua formação. 2. ed. Lisboa: Dom Quixote, 1995. p.51-76.

Pesquisa sobre a formação de professores: o conhecimento sobre aprender a ensinar. Revista Brasileira de Educação, Belo Horizonte, n.9, 1998, p.51-75.

MIZUKAMI, M.G.N.; REALI, A.M.M.R.; REYES, C.R.; MARTUCCI, E.M.; LIMA, E.F.; TANCREDI, R.M.S.P.; MELLO, R.R. Escola e aprendizagem da docência: processos de investigação e formação. São Carlos: EdUFSCar, 2002. MOITA, M.C. Percursos de formação e de trans-formação. In: NÓVOA, A. (Org.). Vida de professores. 2. ed. Porto: Porto Editora, 1995. p.111-40.

NEGRINE, A. Instrumentos de coleta de informações na pesquisa qualitativa. In: MOLINA NETO, V.; TRIVIÑOS, A.N.S. (Orgs.). A pesquisa qualitativa na educação física: alternativas metodológicas. Porto Alegre: Editora Universidade/ UFRGS/Sulina, 1999. p.61-93.

NÓVOA, A. (Org.). Os professores e as histórias da sua vida. In: Vidas de professores. 2. ed. Porto: Porto Editora, 1995. p.11-30.

PÉREZ-GÓMEZ, A. O pensamento prático do professor: a formação do professor como profissional reflexivo. In: NÓVOA, A. (Org.). Os professores e a sua formação. 2. ed. Lisboa: Dom Quixote, 1995. p.93-114.

RAMOS, G.N.S. Preparação profissional em educação física: a questão dos estágios. 2002. 126 f. Tese (Doutorado em Educação Física) - Faculdade de Educação Física, Universidade Estadual de Campinas, Campinas, 2002. A natureza da pesquisa em educação física escolar (mesa redonda 2). In: SEMINÁRIO DE EDUCAÇÃO FÍSICA ESCOLAR FÍSICA ESCOLAR: questões epistemológicas, pesquisa e educação continuada, 8., 2005, São Paulo. Anais... São Paulo: EEFEUSP, 2005.

SANTOS, N.Z.; BRACHT, V.; ALMEIDA, F.Q. Vida de professores de educação física: o pessoal e o profissional no exercício da docência. Movimento, Porto Alegre, v.15, n.2 p.141-65, 2009.

SCHÖN, D.A. Formar professores como profissionais reflexivos. In: NÓVOA, A. (Org.). Os professores e a sua formação. 2.ed. Lisboa: Dom Quixote, 1995. p.77-91.

SILVA, R.C. O professor, seus saberes e suas crenças. In: GUARNIERI, M.R. (Org.). Aprendendo a ensinar: o caminho nada suave da docência. Campinas: Autores Associados, 2000. p.25-44.

TANI, G. Vivências práticas no curso de graduação em educação física: necessidade, luxo ou perda de tempo? In: SIMPÓSIO DE PESQUISA EM EDUCAÇĀO FÍSICA, 6., 1995, Santa Catarina. Anais... Santa Catarina. 1995. p.17-31.

TARDIF, M.; RAYMOND, D. Saberes, tempo e aprendizagem do trabalho no magistério. Educação \& Sociedade, Campinas, v.21, n.73, p.209-44, 2000.

VIEIRA, R. Ser professor: ensino ou aprendizagem da profissão? Educação \& Comunicação, Leiria, v.5, p.9-27, 1999. ZABALZA, M.A. Diários de aula. Porto Alegre: Artmed, 2004.

ZEICHNER, K. Novos caminhos para o practicum: uma perspectiva para os anos 90.In: NÓVOA, A. (Org.). Os professores e a sua formação. 2.ed. Lisboa: Dom Quixote, 1995. p.115-38.

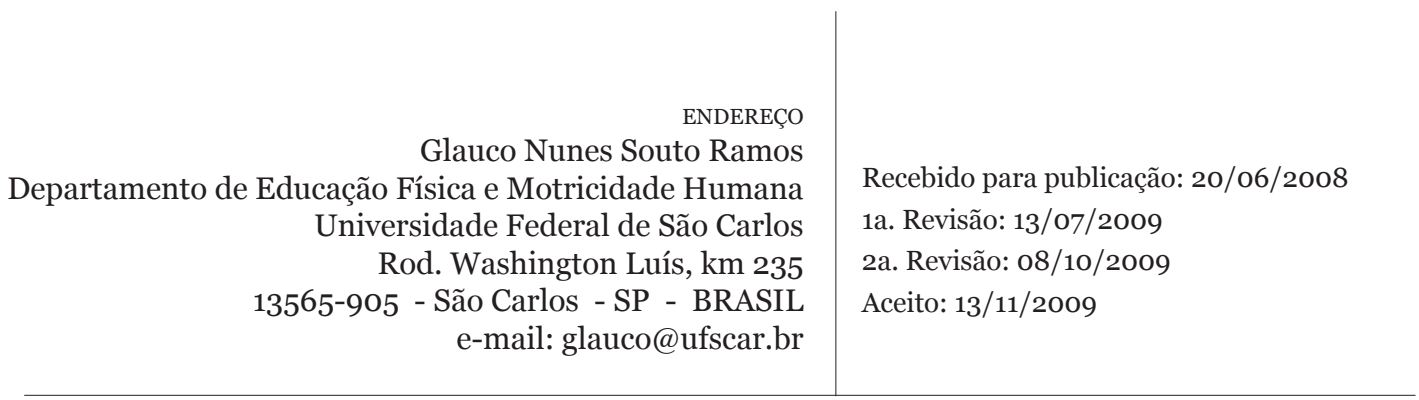

238 • Rev. bras. Educ. Fís. Esporte, São Paulo, v.24, n.2, p.223-38, abr./jun. 2010 